\title{
Preoperative Prediction of Difficult Laparoscopic Cholecystectomy: A Scoring Method
}

\author{
MAHMOUD S. FARAHT, M.D.; HAITHAM M. ELMALEH, M.D.; \\ WALEED M. ABDELGHANI HASSAN, M.Sc. and HOSSAM S. ABDELRAHIM, M.D.
}

The Department of General Surgery, Faculty of Medicine, Ain Shams University

\begin{abstract}
Background: Laparoscopic cholecystectomy is the most frequent operation nowadays for gallbladder stones. It is associated with faster recovery and shorter hospital stay. On the wide use of laparoscopic cholecystectomy, various complications appeared. This made researches work on studies to predict the difficulty of laparoscopic cholecystectomy through different scoring system.
\end{abstract}

This study validates the usage of a scoring system for preoperative prediction of intraoperative difficulties of laparoscopic cholecystectomy that may help the patient as well as surgeon in being better prepared for intraoperative challenges.

Gallbladder-related disease is one of the common surgical elective and emergency indications. Laparoscopic cholecystectomy (LC) is the gold standard nowadays for gallbladder removal.

The frequency of complications associated with laparoscopic cholecystectomy varies from $0.5-6 \%$. Complications of cholecystectomy include iatrogenic perforation of gallbladder with spilt gallstones that is considered the most common, bile duct injury, bile leaks, bleeding and bowel injury. Conversion rate was about $5 \%$ of all laparoscopic cholecystectomies.

Many risk factors have been found to be associated with difficult laparoscopic cholecytectomy. These result in part from patient selection, surgical inexperience, and the technical constraints that are inherent to the minimally invasive approach.

Scoring proposed by Randhawa and Pujahari in 2008 is the most used currently. They found its statistically and clinically good test for predicting outcome in LC. This score had positive predictive value of $88.8 \%$ and $92.2 \%$ for easy and difficult. One of the unique features in this score is the inclusion of palpable Gallbladder that was not reported earlier. But there was no correlation of score and conversion in this study as all cases of conversion were due to anomalous ducts that could have been predicted by MRCP. It included various clinical and ultrasonographic parameters.

Aim of Study: To validate a risk score based on the patient's history, physical examination and abdominal ultrasonography

Correspondence to: Dr. Waleed M. Abdelghani Hassan, E-Mail: waleedadelghany@gmail.com parameters for preoperative prediction of difficult laparoscopic cholecystectomy.

Patients and Methods: Our study included 30 patients underwent laparoscopic cholecystectomy in Ain Shams Hospital and Alamria Hospital.

Results: In our study, males were more predominant than females $(73.3 \%$ vs $26.7 \%)$ with mean age of $(40.23 \pm 13.64)$ years. Our patients had mean BMI of $(28.43 \pm 4.03) \mathrm{kg} / \mathrm{m}^{2}$ with most of them were obese $(63.3 \%)$. Intra operative difficulty showed significant relation with sex and BMI.

$13.3 \%$ of patients had leukocytosis and all our patients had normal alkaline phosphatase. $56.7 \%$ of the study patients were presented with previous acute attacks, $20 \%$ presented with fever, $6.7 \%$ had palpable GB and $33.3 \%$ had abdominal scar. Intra operative difficulty showed significant relation with previous acute attack, abdominal scar and GB wall thickness. We found that preoperative scoring had a sensitivity of $89.5 \%$, specificity of $100 \%$, positive predictive value of $100 \%$, negative predictive value of $84.6 \%$, diagnostic accuracy of $93.3 \%$, and Kappa agreement of 0.862 compared to the intraoperative scoring system.

Conclusion: We strongly recommend using the preoperative scoring system for predicting the degree of difficulty for laparoscopic cholecystectomy.

Key Words: Difficult cholecystectomy-Acute cholecystitis - Lap cholecystectomy.

\section{Introduction}

GALLSTONES are a major cause of morbidity worldwide. Gallstones are concretions that form in the biliary tract, usually in the gallbladder. Gallstones develop insidiously, and they may remain asymptomatic for decades. Migration of a gallstone into the opening of the cystic duct may block the outflow of bile during gallbladder contraction. The resulting increase in gallbladder wall tension produces biliary colic. Cystic duct obstruction, if it persists for more than a few hours, may lead to acute cholecystitis [1]. 
LC has revolutionized minimally invasive procedures. Decreased postoperative pain, earlier oral intake, shorter hospital stays, early resumption of normal activity, and improved cosmesis have been well recognized after LC. Also, a significant reduction in the incidence of wound complications and postoperative ileus. The overall mortality of cholecystectomy has decreased since the advent of the laparoscopic approach [2] .

Laparoscopic cholecystectomy (LC) has become the procedure of choice for management of symptomatic gallstone disease for its minimal invasive, less pain and early recovery.

Difficult cholecystectomy specially in acute attacks is a challenging procedure that has many risks and complications specially failure and injury

It is very difficult to say preoperatively whether it is going to be easy or difficult. The degree of difficulties is again impossible to predict. There are many scoring systems for difficulty predection. We have worked out one such system (Randhawa scoring system) for predicting the degree of difficulty in LC.

\section{Aim of the work:}

The aim of this study is to validate a risk score based on the patient's history, physical examination and abdominal ultrasonography preoprative parameters for prediction of difficult laparoscopic cholecystectomy.

\section{Patients and Methods}

Its prospective analytical study conducted in Ain Shams University Hospital and Alamria Hospital in Alexandria. The study period was six months (from June 2019 to December 2019) aiming to establish scoring method related to preoperative prediction of difficult laparoscopic cholecystectomy.

All patients were sampled from outpatient clinic in Ain Shams University Hospital and Alamria hospital in Alexandria including 30 patients underwent laparoscopic cholecystectomy for gallbladder stone disease by the same surgical team.

\section{Inclusion criteria:}

All patients with gallbladder stone disease indicated for laparoscopic cholecystectomy.

\section{Exclusion criteria:}

- Absolute contraindications to laparoscopic cholecystectomy; coagulopathies and end stage liver disease.
- Relative contraindications as Respiratory diseases or Pregnancy.

- Non-calcular gallbladder disease either neoplasms or non-calcular cholangitis.

\section{Ethical consideration:}

Approval will be obtained from the ethical committee of the Department of General Surgery, Faculty of Medicine, Ain Shams University.

\section{Preoperative workup:}

All patients underwent preoperative workup taking history: Age, pain (site - character of pain - referral site - relation to meal) previous attack, past history of previous operation, jaundice and medical disease. General examination: Pulse, blood Pressure, temperature, BMI and jaundice. Local examination:

- Inspection: Abdominal scar- and guarding.

- Palpation: Palpable GB-tenderness and rebound tenderness.

- Percussion: Abdominal distention.

- Auscultation: Intestinal sounds.

Investigation: Abdominal Ultrasound, ECG, chest X-ray, ERCP if needed, and laboratory tests (CBC, bleeding profile, HCV, HBV, HIV, SGOT, SGPT, urea, creatinine, total and direct bilirubin, alkaline phosphatase).

\section{Preoperative scoring system:}

All 30 patient were categorized preoperatively by Randhawa scoring system into 3 groups according to clinical and radiological data.

- Group A: Expected to be easy (with score of 05) or

- Group B: Difficult with score of 6-10) or

- Group C: Very difficult (with score of 11-15).

\section{Operative data:}

These patients underwent laparoscopic cholecystectomy and intraoperative difficulties (whether easy, difficult or very difficult) was assessed according to the following score.

- Easy: Time taken <60 minutes, no bile spillage and no injury to duct or artery.

- Difficult: Time taken 60-120 minutes or bile or stone spillage or injury to duct or artery.

- Very difficult: Time taken >120 minutes or conversion to open.

The score preoperative and intraoperative is correlated in each patient to come to a conclusion whether preoperative predictive score was predictive or not. 
Table (1): Randhawa scoring system [3]

\begin{tabular}{|c|c|c|c|}
\hline Scoring factors & Minmum & Maximum & Total \\
\hline \multicolumn{4}{|l|}{ History: } \\
\hline Age & $<50$ years $(0)$ & $>50$ years $(1)$ & 1 \\
\hline Sex & Female (0) & Male (1) & 1 \\
\hline $\begin{array}{l}\text { History of } \\
\text { hospitalization } \\
\text { of acute } \\
\text { cholecystitis }\end{array}$ & No $(0)$ & Yes (4) & 4 \\
\hline \multicolumn{4}{|l|}{ Clinical: } \\
\hline BMI & $<25(0)$ & $\begin{array}{l}25.0-27.5(1) \\
>27.5(2)\end{array}$ & 2 \\
\hline Abdominal Scar & No $(0)$ & $\begin{array}{l}\text { Infra-umbilical (1) } \\
\text { Supra-umbilical (2) }\end{array}$ & $\begin{array}{l}1 \\
2\end{array}$ \\
\hline Palpable GB & No $(0)$ & Yes (1) & 1 \\
\hline \multicolumn{4}{|l|}{ Sonography: } \\
\hline Wall thickness & Thin $(0)$ & Thick $>4 \mathrm{~mm}(2)$ & 2 \\
\hline $\begin{array}{l}\text { Pericholecystic } \\
\text { collection }\end{array}$ & No $(0)$ & Yes (1) & 1 \\
\hline Impacted stone & No $(0)$ & Yes (1) & 1 \\
\hline
\end{tabular}

Total score $=15$. BMI $=$ Body mass Index. $\mathrm{GB}=$ Gallbladder . Easy 0-5. Difficult 6-10. Very difficult 11-15.

\section{Study procedure:}

Our standard technique of performing $\mathrm{LC}$ is to use 4 ports. The pneumoperitoneum is achieved by closed Veress needle technique at palmar point (left subcostal at midclavicular line). A $10 \mathrm{~mm}$ telescope a 30 degree is used at the umbilicus either infraumbilical or supraumbilical. Another $10 \mathrm{~mm}$ trocar is used in the epigastrium which is the main right working port for the surgeon. One $5 \mathrm{~mm}$ trocar in the right lumbar region (at anterior axillary line) is used for gallbladder fundus traction and another $5 \mathrm{~mm}$ trocar in the right hypochondrium (mostly at midclavicular line) is used as left-hand working port for the surgeon. With left hand Hartmann's pouch is retracted and with right hand anterior and posterior dissection is done in Calot's triangle and wide window is created. Critical view of safety is of the most importance to prevent bile duct injury (identification of two ductal structures entering GB and no structures passing behind these ductal structures except GB bed). Clipping of the cystic duct and cystic artery is achieved from $10 \mathrm{~mm}$ epigastric port and then we dissect the GB carefully from liver bed. Gallbladder extraction is generally done from epigastric port. If failed to identify Critical view of safety, we must avoid clipping and try to do fundus first or partial cholecystectomy or conversion to open. Finally, Morison space drain is applied.

Postoperative workup: All patients had care in ward, NPO for 6 hours then stared oral fluids, we followed-up the drain for 24 hours and the wound. We followed-up postoperative complications as postoperative bleeding, bile duct injury, wound infection and post site hernia.

Statistical analysis: Data collected scored, tabulated and statistically analyzed.

Table (2): Distribution of the studied cases according to demographic data $(n=30)$.

\begin{tabular}{|c|c|c|}
\hline & No. & $\%$ \\
\hline \multicolumn{3}{|l|}{ Sex: } \\
\hline Male & 22 & 73.3 \\
\hline Female & 8 & 26.7 \\
\hline \multicolumn{3}{|l|}{ Age (years): } \\
\hline$<50$ & 21 & 70.0 \\
\hline$>50$ & 9 & 30.0 \\
\hline Min. - Max. & \multicolumn{2}{|c|}{$17.0-58.0$} \\
\hline Mean \pm SD & \multicolumn{2}{|c|}{$40.23 \pm 13.64$} \\
\hline Median (IQR) & \multicolumn{2}{|c|}{$45.50(26.75-54.25)$} \\
\hline \multicolumn{3}{|l|}{$B M I\left(k g / \mathrm{m}^{2}\right):$} \\
\hline Normal $(<25)$ & 7 & 23.3 \\
\hline Overweight (25-27.5) & 4 & 13.3 \\
\hline Obese $(>27.5)$ & 19 & 63.3 \\
\hline Min. = Max. & \multicolumn{2}{|c|}{$22.0-35.0$} \\
\hline Mean \pm SD & \multicolumn{2}{|c|}{$28.43 \pm 4.03$} \\
\hline Median (IQR) & \multicolumn{2}{|c|}{$28.50(24.75-32.0)$} \\
\hline
\end{tabular}

\section{Results}

1- Preoperative demographic data:

Table (3): Distribution of the studied cases according to different laboratory parameters $(n=30)$.

\begin{tabular}{lll}
\hline & No. & $\%$ \\
\hline WBCs $(4000-11000 / L):$ & & \\
Normal & 26 & 86.7 \\
High & 4 & 13.3 \\
ALP (up to 115 IU/L): & & \\
$\quad$ Normal & 30 & 100.0 \\
High & 0 & 0.0 \\
\hline
\end{tabular}

Table (4): Distribution of the studied cases according to different risk factors $(\mathrm{n}=30)$.

\begin{tabular}{lll}
\hline & No. & $\%$ \\
\hline Fever & 2 & 6.7 \\
Previous acute attack & 17 & 56.7 \\
Palpable GB & 2 & 6.7 \\
Abdominal scar: & & \\
No & 20 & 66.7 \\
Yes & 10 & 33.3 \\
Infraumbilical & $8 / 30$ & 26.6 \\
Supraumbilical & $2 / 30$ & 6.7 \\
\hline
\end{tabular}




\section{2- Preoperative clinical data:}

Table (5): Distribution of the studied cases according to preoperative score $(n=30)$.

\begin{tabular}{lcc}
\hline Preoperative score & No. & $\%$ \\
\hline $\begin{array}{l}\text { Expected to be easy: } \\
\quad(0-5)\end{array}$ & 13 & 43.3 \\
$\quad \begin{array}{l}\text { Expected to be difficult: } \\
\quad(6-10)\end{array}$ & 12 & 40.0 \\
$\quad \begin{array}{l}\text { Expected to be very difficult: } \\
(11-15)\end{array}$ & 5 & 16.7 \\
\hline
\end{tabular}

3- Preoperative scoring (Randhawa score) results:

Table (6): Distribution of the studied cases according to different parameters of intraoperative difficulty $(n=30)$.

\begin{tabular}{|c|c|c|}
\hline & No. & $\%$ \\
\hline $\begin{array}{l}\text { Adhesion } \\
\text { (by inability to visualize } \\
\text { the fundus or at least Hartmann } \\
\text { pouch without dissection) }\end{array}$ & n & 30.0 \\
\hline Impacted neck stone & 0 & 0.0 \\
\hline Conversion to open & 2 & 6.6 \\
\hline Bile or stone spillage & 10 & 33.3 \\
\hline Injury to duct & 2 & 6.6 \\
\hline Injury to artery & 1 & 3.3 \\
\hline Visceral injury & 0 & 0 \\
\hline Blood loss & \multirow{2}{*}{\multicolumn{2}{|c|}{$\begin{array}{l}\text { Ranging from } 50 \mathrm{ml} \text { to } 100 \mathrm{ml} \\
\text { with average } 60 \mathrm{ml} \\
0\end{array}$}} \\
\hline $\begin{array}{l}\text { Intraoperative anatomical } \\
\text { anomaly }\end{array}$ & & \\
\hline
\end{tabular}

4- Intraoperative data:

5- Intraoperative difficulties score:

- Easy: Time taken $<60$ minutes, no bile spillage and no injury to duct or artery.

- Difficult: Time taken 60-120 minutes or bile or stone spillage or injury to duct or artery.

- Very difficult: Time taken > 120 minutes or conversion to open.

Table (7): Distribution of the studied cases according to intra operative difficulty $(n=30)$.

\begin{tabular}{lll}
\hline Intra operative difficulty & No. & $\%$ \\
\hline Easy & 11 & 36.7 \\
Difficult & 12 & 40.0 \\
Very Difficult & 7 & 23.3 \\
\hline
\end{tabular}

\section{Postoperative data:}

As regard postoperative data of our patient:

Except for 3 cases first case was injury to proper hepatic artery "minor injury" we converted to open and did primary repair, second case was minor injury to CBD, and we did primary repair laparoscopically, third case was injury to cystic duct treated laparoscopically, other patients were discharged after 24 hours and there is no postoperative complications in form of postoperative hemorrhage, leakage, wound infection or Postoperative ileus.

Table (8): Agreement (sensitivity, specificity and accuracy) of preoperative score with intra operative difficulty.

\begin{tabular}{|c|c|c|c|c|c|c|c|c|c|}
\hline \multirow{3}{*}{ Preoperative score } & \multicolumn{4}{|c|}{ Intra operative difficulty } & \multirow{3}{*}{ Sensitivity } & \multirow{3}{*}{ Specificity } & \multirow{3}{*}{ PPV } & \multirow{3}{*}{ NPV } & \multirow{3}{*}{ Accuracy } \\
\hline & \multicolumn{2}{|c|}{$\begin{array}{c}\text { Easy } \\
(\mathrm{n}=11)\end{array}$} & \multicolumn{2}{|c|}{$\begin{array}{c}\text { Difficult } \\
\text { +very difficult } \\
\quad(\mathrm{n}=19)\end{array}$} & & & & & \\
\hline & No. & $\%$ & No. & $\%$ & & & & & \\
\hline Easy (13) & 11 & 100 & 2 & 10.5 & 89.47 & 100.0 & 100.0 & 84.62 & 93.33 \\
\hline Difficult + very difficult (17) & 0 & 0.0 & 17 & 89.5 & & & & & \\
\hline ic $(p)$ & \multicolumn{4}{|c|}{$0.862 *(<0.001) *$} & & & & & \\
\hline Level of agreement & \multicolumn{4}{|c|}{ Very good agreement } & & & & & \\
\hline
\end{tabular}

ic: Kappa test.

PPV: Positive predictive value.

NPV: Negative predictive value.

*: Statistically significant at $p \leq 0.05$. 
Figures of a case of difficult LC due to repeated acute attacks:

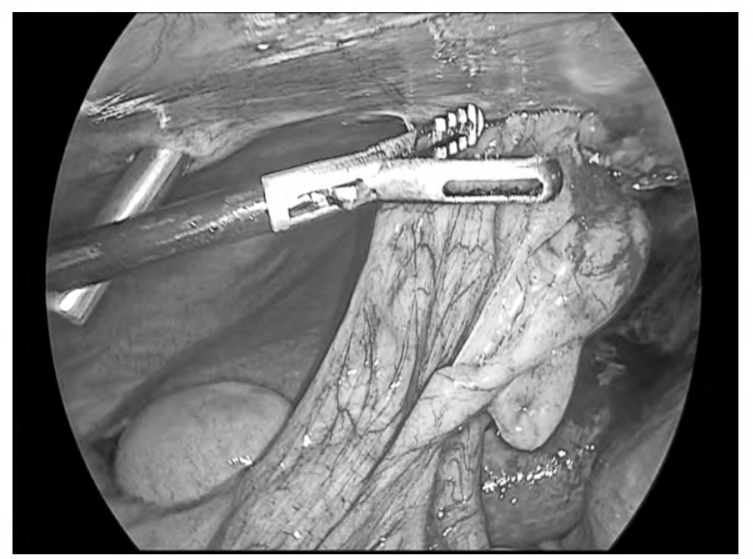

Fig. (1): Massive adhesions due to repeated acute attacks.

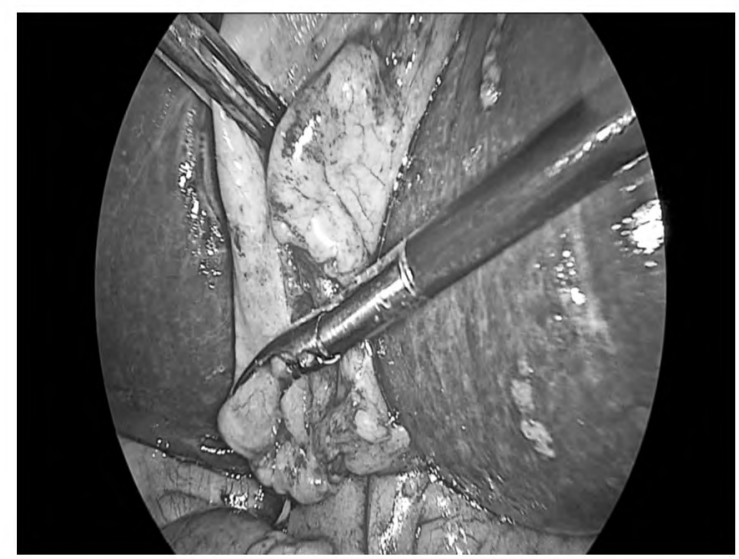

Fig. (2): Trials for omental adhesiolysis.

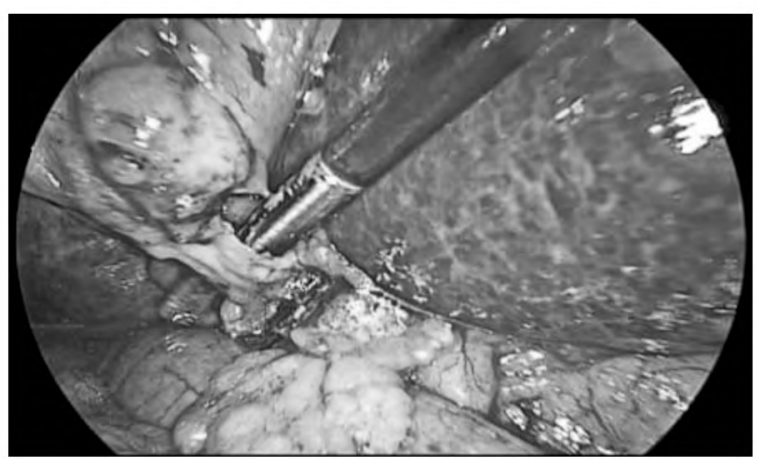

Fig. (3): Identification of calot.

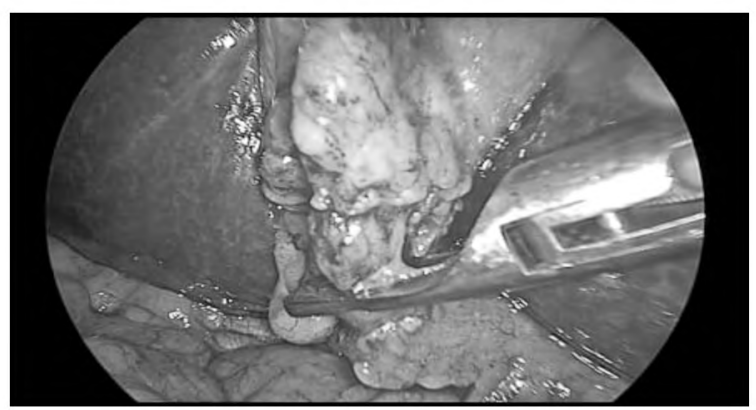

Fig. (4): Clipping of cystic duct.

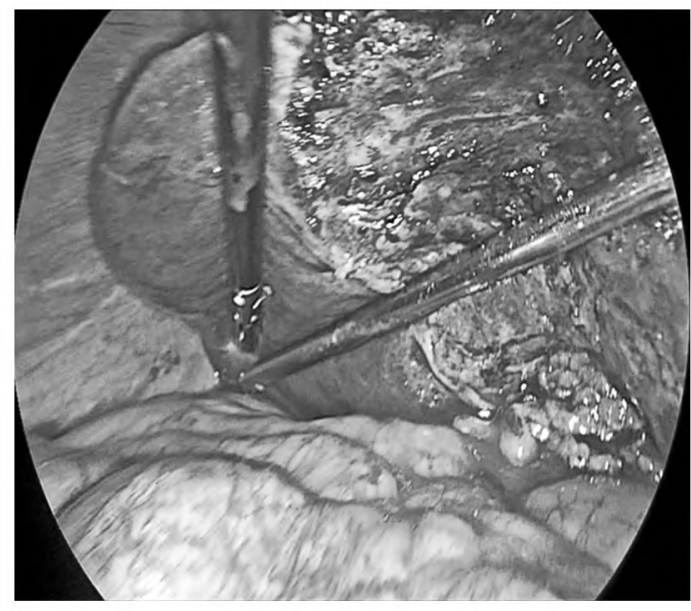

Fig. (5): Wash after GB excision from its bed.

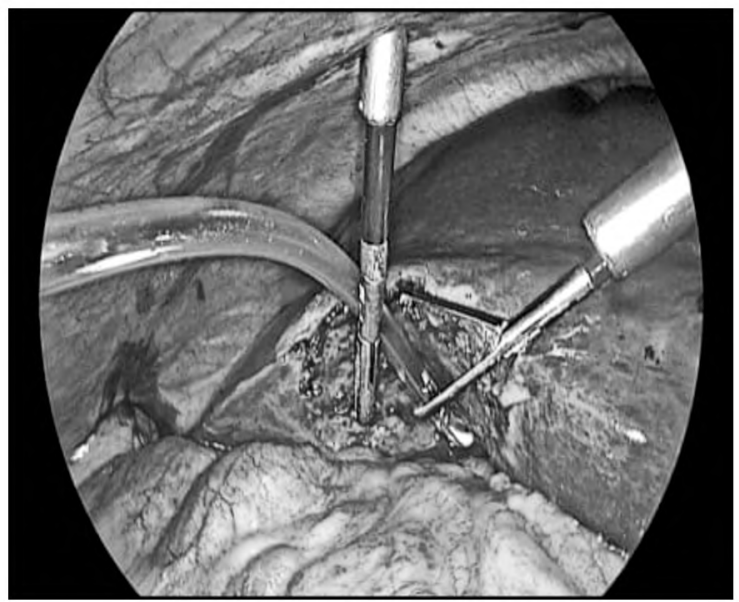

Fig. (6): Drain insertion after wash

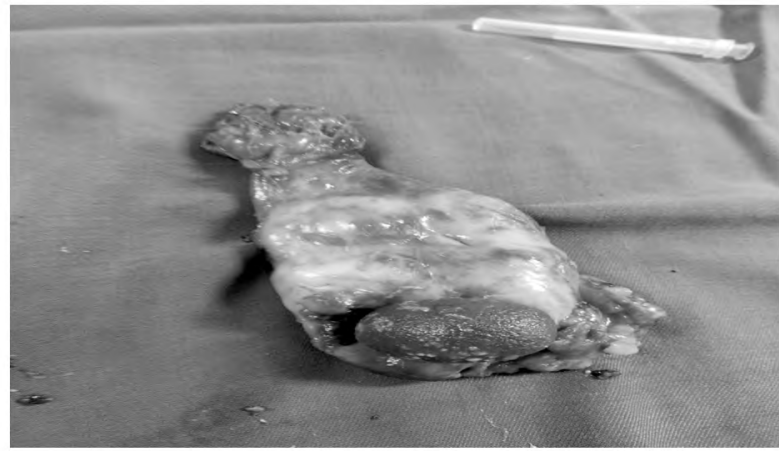

Fig. (7): Inflamed GB with multiple large stones after LC.

\section{Discussion}

Laparoscopic cholecystectomy (LC) has become the procedure of choice for management of symptomatic gallstone disease. Appro0ximately, 2-15\% of attempted LC has to be converted to an open procedure due to various difficulties faced while performing the procedure [3] 
Various clinical and ultrasonological parameters that may help to predict the difficulty level preoperatively were analyzed in the present study. Such prediction done preoperatively may help the patient as well as the surgeon in being better prepared for the intra-operative challenges [4]

So, this study aimed to validate a risk score based on the patient's history, physical examination and abdominal ultrasonography parameters for prediction of difficult laparoscopic cholecystectomy.

Our prospective study included 30 patients underwent laparoscopic cholecystectomy in Ain Shams Hospital and Alamria hospital. Males was more predominant than females ( $73.3 \%$ vs $26.7 \%)$ with mean age of $(40.23 \pm 13.64)$ years with more patients older than 50 years old $(70 \%)$.

In agreement to Argwal et al. (2015) study, the majority of patients were in the age group of $\leq 50$ years (25 patients) and only $16.7 \%$ (five cases) were $>50$ years $[5]$.

Nidoni et al. (2015) study to assess the clinical and radiological parameters for predicting the difficult laparoscopic cholecystectomy and its conversion found that out of total 180 patients 115 were females and 65 were males. Male: Female ratio is $1: 1.76[6]$.

Our patients had mean BMI of $(28.43 \pm 4.03)$ $\mathrm{kg} / \mathrm{m}^{2}$ with 19 patients were obese (BMI $\left.>27.5\right)$ $(63.3 \%)$.

As regards preoperative clinical data in our study 4 patients had leukocytosis $13.3 \%$ and all our patients had normal alkaline phosphatase.

Similar to Nidoni et al. (2015) study in which out of 180 patients included in this study, 36 patients had total leucocyte count more than $11000 / \mathrm{cmm}$ and 144 patients had less than $11000 / \mathrm{cmm}$ [6].

In the present study, 17 patients were presented with previous acute attacks $(56.7 \%), 2$ patients presented with fever (6.7\%), 2 patients had palpable GB $(6.7 \%)$ and 10 patients had abdominal scar $(33.3 \%)$.

US findings of this study found that the thickened GB wall >4mm in 15 patients (15\%), impacted stone at neck of GB in 1 patient $(3.3 \%)$ with no patients with pericholecystic collection.

In Nidoni et al. (2015) study, out of 180 patients included in this study 28 patients had gall bladder wall thickness more than $3 \mathrm{~mm}$ and 152 patients had less than $3 \mathrm{~mm}$. $97 \%$ of individuals have GB wall thickness $<2 \mathrm{~mm}$. Thickened GB wall on preoperative US is a sign of present inflammation or fibrosis due to cholecystitis [6].

Preoperative scoring (Randawa score) results of our study found that 13 patients $(43.3 \%)$ expected to be easy, 12 patients (40\%) expected to be difficult and 5 patients $(16.7 \%)$ expected to be very difficult.

In Randawa study one hundred and seventyeight $(78 \%)$ were scored easy and $50(21.9 \%)$ were difficult and nil in the very difficult group [3]

Similar to Bourgouin et al. (2016) study using (DiLCs score), in which 148 (35.2\%) were identified as "difficult cholecystectomies" and were compared to 272 "easy cholecystectomies [4].

Regarding Intraoperative data of the present study patients, 9 patients had adhesions (30\%), no patients had impacted neck stone, 2 patients converted to open $(6.6 \%), 10$ patients had bile or stone spillage (33.3\%), 2 patients had injury to duct (6.6\%), 1 patient had injury to artery $(3.3 \%)$, no visceral injury, no intraoperative anatomical anomaly and blood loss ranging from $50 \mathrm{ml}$ to $100 \mathrm{ml}$ with average $60 \mathrm{ml}$.

In Randhawa study, the conversion rate due to impacted stone and pericholecystic collections was $3 / 228(1.315 \%)$ [3]

Bourgouin et al. (2016) study, 27 patients experienced intra-operative complications, complications included five bile leaks, two intraoperative gallstone migrations, and one acute respiratory failure [4].

In our study, 13 patients had operative time $<60$ minutes $(43.3 \%), 11$ patients had operative time 60-120 minutes (36.7\%) and 6 patients had operative time $>120$ minutes $(20 \%)$.

In Randhawa study, 164 (71.9\%) of patients had operative time $<60$ minutes, $54(23.7 \%)$ had operative time $>60-120$ minutes and $10(4.4 \%)$ had operative time $>120$ minutes [3].

By intraoperative difficulty score 11 patients were easy operative (36.7\%), 12 patients were difficult (40\%) and 7 patients were very difficult $(23.3 \%)$.

Post-operative data of our study found that, all 30 patients were discharged after 24 hours. There were no postoperative complications in form of postoperative hemorrhage, leakage, wound infection or postoperative ileus. 
In our study, 13 patients (43.3\%) who expected to be easy by Randhawa score, 11 patients of them $(36.6 \%)$ were actually easy by intraoperative difficulty score and 2 patients $(6.7 \%)$ were difficult and very difficult, 17 patients $(56.6 \%)$ who expected to be difficult and very difficult by Randhawa score, actually all were difficult and very difficult by intraoperative difficulty score so we found that preoperative scoring (Randhawa score) had a sensitivity of $89.5 \%$, specificity of $100 \%$, positive predictive value of $100 \%$, negative predictive value of $84.6 \%$, diagnostic accuracy of $93.3 \%$, and Kappa agreement of 0.862 compared to the intraoperative scoring system.

While in Sudhir et al. (2018), study preoperative scoring had a sensitivity of $95.71 \%$, specificity of $50 \%$, positive predictive value of $81.71 \%$, negative predictive value of $83.3 \%$, diagnostic accuracy of $82 \%$, and Kappa agreement of 0.5161 compared to the intraoperative scoring system [7].

In agreement to Abd-El-Aal and Hassan (2018) study who found significant correlation between male sex and the difficult level of surgery in univariate analysis in intraoperative outcome $(p=0.03)$. BMI greater than 27.5 was found to be a significant factor for prediction of difficult LC only in univariate analysis in preoperative outcome with risk factors $(p=0.02)[8]$.

In the same line with studies done worldwide, male sex has been described to be associated with difficult LC [9].

In Argwal et al. (2015) study, there were 6 males and 24 females. Of 6 males, 2 were predicted to have a difficult surgery. Post-surgery $50.0 \%$ males ( 3 out of 6 ) turned out to have a difficult procedure and in contrast there is no correlation between BMI and difficult level of surgery [5].

Surgical experience of the operating surgeon could be one of the reasons for this discrepancy as such increased BMI is not a technical problem.

In this study, intra operative difficulty showed significant relation with fever $(p=.05)$, previous acute attack $(p<.001)$, abdominal scar $(p=.004)$ and GB wall thickness $(p=.008)$.

In Randhawa et al. (2009) study palpable GB $(p<0.01)$ and thick-walled GB $(p<0.038)$ are found of statistical significance in predicting difficult LC. One author found acute cholecystitis in obese as the most important factor for conversion. Even history of an acute attack requiring hospitalization made the surgery difficult $(p<0.001)$. There are reports of higher rate of bleeding, ductal injury and subsequent conversion in acute cholecystitis. Clinically palpable gallbladder is not reported earlier as a predictor of difficult cholecystectomy. This is one of the unique features of the study and found significant ( $p 0.022)$. Thick-walled GB is one of the predictors of conversion. We found it to be a significant factor ( $p$ 0.038). Upper abdominal surgery is reported to have high rate of conversion and attributed to dense adhesion. With increasing experience on adhesiolysis and advanced laparoscopic surgery, conversion is less often seen. We also found it to be not significant ( $p$ 0.882). Sonographic impacted stone and pericholecystic collections are other factors scored giving the acuteness of the condition, but there was no good correlation between sonographic findings and operative findings and hence found not significant [3].

Nidoni et al. (2015) study data analysis revealed that there was significantly high risk of difficulty and conversion in patients with previous history of more than 2 attacks of acute cholecystitis ( $p=0.03,95 \%$ confidence interval) [6].

Supra and infraumbilical scar, indication of previous abdominal operations, may lead to adhesions present between viscera or omentum and abdominal wall. There may be chances of injury to these structures during insertion of first port, and the risk of conversion was reported to be higher [10].

In the Abd-El-Aal and Hassan (2018) study, abdominal scar was found to be statistically insignificant in both univariate and multivariate analysis of preoperative and intraoperative outcomes with risk factor. There was significant correlation between the GB wall thickness and the difficulty level of surgery in both univariate and multivariate analyses of preoperative and intraoperative outcomes with risk factor $(p=0.007$ and 0.02 , and $p=0.001$ and 0.02 , respectively) [8].

Clinically palpable GB was found to be predictor of difficult LC Palpable GB could be due to a distended GB, mucocele GB, thick-walled, or due to the adhesions between the GB and the omentum [9].

In Argwal et al. (2015) study, 90\% of patients with palpable GB (9 out of 10) turned out to have a difficult procedure post-surgery. There is a smaller number of studies supporting clinically palpable GB as a predictor of difficult LC. This is one of the unique features of this study and found strongly significant [5]. 
It was claimed that GB wall thickness $>4 \mathrm{~mm}$ is a frequent finding in acute cholecystitis. Progression of inflammation is characterized by multiple adhesions of surrounding anatomic structures with the GB and fibrosis or necrosis of the GB wall, which creates difficulties when dissecting Calot triangle elements and the GB from its bed. Inflammation in the end leads to creation of adhesions and fibrosis [11]

In agreement with Khetan and Yeola (2017) study found that previous history of hospitalization for cholecystitis and increased gall bladder wall thickness were found statistically significant in predicting difficult LC [12]

In the present study, only adhesions as intraoperative data which showed statistically significant difference between groups.

Conversion rate was 2/30 two cases, first case was injury to proper hepatic artery we made primary repair, second case was failure to identify calot triangle due to repeated acute attack, injury happened in 3 cases first case was injury to proper hepatic artery "minor injury" we converted to open and did primary repair, second case was minor injury to $\mathrm{CBD}$ and we did primary repair laparoscopically, third case was injury to cystic duct treated laparoscopically.

While Elgammal et al. (2019) study found that previous history of attacks of cholecystitis ( $p=0.001)$ and wall thickness $(p=0.007)$ were found to be statistically significant in predicting difficult LC in both univariate and multivariate analyses. Other factors such as age ( $p=0.002)$, BMI greater than $27.5(p=0.02)$, palpable GB $(p=0.003)$, impacted stone $(p=0.01)$ were found to be statistically significant in predicting difficult LC. Factors such as sex, and abdominal scar were not statistically significant in predicting difficult LC [13] .

Among studies reporting on the operative difficulty, Sakuramoto et al. (2000) and Bourgouin et al. (2016) studies used operative time as the primary end point. These studies chose not to use conversion from laparoscopic to open surgery as the primary endpoint, instead using the surgeon's operative time to distinguish between easy and difficult LC. Previous studies showed that conversion is highly correlated to the surgeon's experience since every surgeon may have a different threshold for conversion, and experienced surgeons may not convert even in very difficult procedures $[4,14]$.

\section{Conclusion:}

Laparoscopic cholecystectomy (LC) is the gold standard treatment for gallstone disease.

We strongly recommend using the preoperative scoring system for predicting the degree of difficulty for laparoscopic cholecystectomy. In addition, it is also recommended to conduct more studies on the application of the intraoperative scoring system.

Randhawa score is a good scoring system for prediction of difficult laparoscopy, we found that many factors are given as predictors for difficult LC as male sex, BMI more than 27.5, history of previous acute attack, thick wall GB, and upper abdominal surgery.

\section{References}

1- EGBERT A.M.: Gallstone symptoms: Myth and reality. Postgraduate Medicine, 90 (5): 119-126, 1991.

2- LAM C.M., MURRAY F.E. and CUSCHIERI A.: Increased cholecystectomy rate after the introduction of laparoscopic cholecystectomy in Scotland. Gut, 38 (2): 282-284, 1996.

3- RANDHAWA J.S. and PUJAHARI A.K.: Preoperative prediction of difficult lap chole: A scoring method. Indian Journal of Surgery, 71 (4): 198-201, 2009.

4- BOURGOUIN S., MANCINI J., MONCHAL T., CAL VARY R., BORDES J. and BALANDRAUD P.: How to predict difficult laparoscopic cholecystectomy? Proposal for a simple preoperative scoring system. The American Journal of Surgery, 212 (5): 873-881, 2016.

5- ARGWAL N., SINGH S. and KHICHY S.: Preoperative prediction of difficult laparoscopic cholecystectomy: A scoring method. Nigerian Journal of Surgery, 21 (2): 130$133,2015$.

6- NIDONI R., UDACHAN T.V., SASNUR P., BALOORKAR R., SINDGIKAR V. and NARASANGI B.: Predicting difficult laparoscopic cholecystectomy based on clinicoradiological assessment. Journal of clinical and diagnostic research: JCDR, 9 (12): PC09, 2015.

7- SUDHIR M.S. and RAJ P.: Preoperative Grading System versus Intraoperative Grading System as Predictors for Difficult Laparoscopic Cholecystectomy: A Comparative Validation Study. Journal of Clinical and Basic Research, 2 (1): 39-47, 2018.

8- ABD-EL-AAL A.S. and ABDALLAH H.A.: Evaluation of preoperative predictive factors for difficult laparoscopic cholecystectomy in comparison with intraoperative parameters. The Egyptian Journal of Surgery, 37 (4): 504, 2018.

9- O'LEARY D.P., MYERS E., WALDRON D. and COFFEY J.C.: Beware the contracted gallbladder-Ultrasonic predictors of conversion. the Surgeon, 11 (4): 187-190, 2013.

10- HUSSAIN A.: Difficult laparoscopic cholecystectomy: Current evidence and strategies of management. Surgical Laparoscopy Endoscopy \& Percutaneous Techniques, 21 (4): 211-217, 2011 
11- STANISIC V., MILICEVIC M., KOCEV N. and STANISIC B.: A prospective cohort study for prediction of difficult laparoscopic cholecystectomy. Annals of Medicine and Surgery, 60: 728-733, 2020.

12- KHETAN A.K. and YEOLA M.: Preoperative prediction of difficult laparoscopic cholecystectomy using a scoring system. International Surgery Journal, 4 (10): 3388-3391, 2017.

13- ELGAMMAL A.S., ELMELIGI M.H. and KOURA
M.M.A.: Evaluation of preoperative predictive factors for difficult laparoscopic cholecystectomy. International Surgery Journal, 6 (9): 3052-3056, 2019.

14- SAKURAMOTO S., SATO S., OKURI T., SATO K., HIKI Y. and KAKITA A.: Preoperative evaluation to predict technical difficulties of laparoscopic cholecystectomy on the basis of histological inflammation findings on resected gallbladder. The American Journal of Surgery, 179 (2): 114-121, 2000.

\section{دراسة طريقة نقاط مسجلة للتنبؤ بصعوبة جراحة استئصال المرارة بالمنظظار}

استئصال المرارة هو العلاج القياسى والمثالى لحصواث المرارة المصحوبة بأعراض ففى عام II . Y كان استئصال المرارة هو ثامن

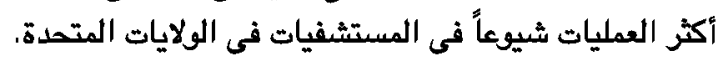

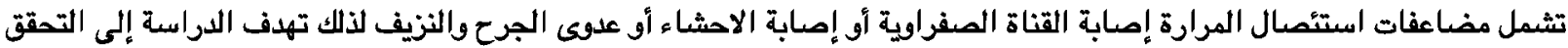
من درجة الخطر بناءً على تاريخ المريض والفحص البدئى والأثعة بالموجات فوق الصوتية اللبطن اللتنبوّ بصعوبية استئصال المرارة بالمنظار. شملت دراستنا . ب مريضاً خضعوا لعملية استئصال المرارة بالمنظار فى مستشفى الد مرداش جامعة عين شمس ومستشفى العامرية

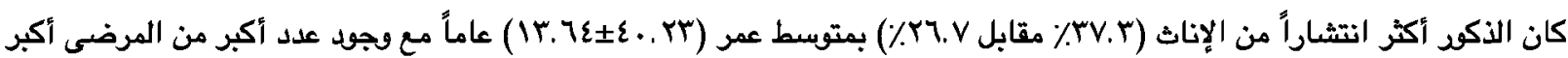

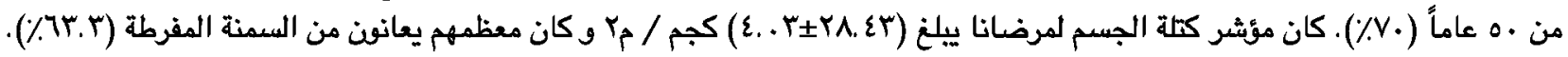

أظهرت الصعوبة أثناء العملية علاقة فعلية وذيادة فى الصعوبة مع الذكود والسمنة.

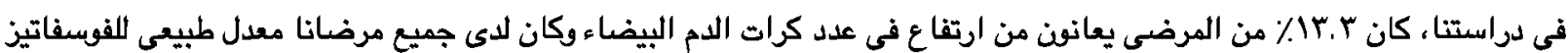

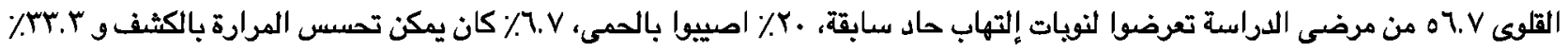
لديهم جرح سيابقة في البطن.

أظهرت النتائج علاقة فعلية وارتفاع في الصعوبية مـ هؤلاء الذين تعرضوا لإلتهابات حادة سابقة ومـع الذين لديهم جروح سابقة في البطن ومع من عانوا من تضخم بحجم المرارة.

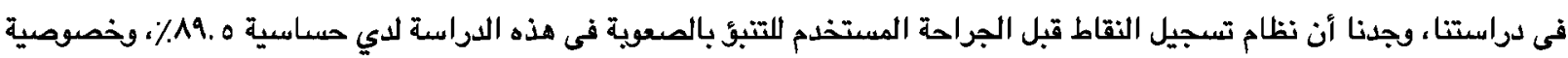

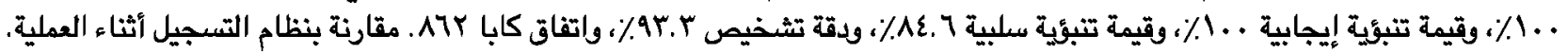

